\title{
Cyclicity of spontaneous recurrent seizures in pilocarpine model of temporal lobe epilepsy in rat
}

\author{
Karolien Goffin *, Jari Nissinen, Koen Van Laere, Asla Pitkänen \\ Katholieke Universiteit Leuven, Belgium
}

Received 25 January 2007; revised 28 February 2007; accepted 8 March 2007

Available online 16 March 2007

\begin{abstract}
Pilocarpine administration to rats results in status epilepticus (SE) and after a latency period to the occurrence of spontaneous seizures. The model is commonly used to investigate mechanisms of epileptogenesis as well as the antiepileptic effects of novel compounds. Surprisingly, there have been no video-EEG studies determining the duration of latency period from SE to the appearance of the first spontaneous seizures or the type and frequency of spontaneous seizures at early phase of pilocarpine-induced epilepsy even though such information is critical for design of such studies. To address these questions, we induced SE with pilocarpine in 29 adult male Wistar rats with cortical electrodes. Rats were continuously video-EEG monitored during SE and up to 23 days thereafter. The first spontaneous seizures occurred 7.2 \pm 3.6 days after SE. During the followup, the mean daily seizure frequency was $2.6 \pm 1.9$, the mean seizure duration $47 \pm 7 \mathrm{~s}$, and the mean behavioral seizure score $3.2 \pm 0.9$. Typically first seizures were partial (score 1-2). Interestingly, spontaneous seizures occurred in clusters with cyclicity, peaking every 5 to 8 days. These data show that in the pilocarpine model of temporal lobe epilepsy the latency period is short. Because many of the early seizures are partial and the seizures occur in clusters, the true phenotype of epilepsy triggered by pilocarpine-induced SE may be difficult to characterize without continuous long-term video-EEG monitoring. Finally, our data suggest that the model can be used for studies aiming at identifying the mechanisms of seizure clustering.
\end{abstract}

(C) 2007 Elsevier Inc. All rights reserved.

Keywords: Cyclic pattern; Pilocarpine; Spontaneous recurrent seizures; Seizure clustering

\section{Introduction}

In the pilocarpine model of epilepsy in rats or mice, epileptogenesis is triggered by status epilepticus (SE) that is induced chemically using a cholinergic substance, pilocarpine (Turski et al., 1983, 1984). The model replicates several features of human temporal lobe epilepsy, including similarities in pathology, behavioral abnormalities, and occurrence of both partial and generalized seizures (Turski et al., 1989). Currently, it is one of the most often used models in studies investigating the basic mechanisms of epilepsy and testing novel compounds for treatment of epileptogenesis and epilepsy (Cavalheiro et al., 2006).

Previous characterizations of the pilocarpine model have used video monitoring or visual observations of seizures to

\footnotetext{
* Corresponding author.

E-mail address: karolien.goffin@uz.kuleuven.be (K. Goffin).
}

analyze the latency period, seizure frequency, or seizure duration. In these studies, the mean latency period varied between 10 and 18 days and the mean seizure frequency between 0.1 and 1.9 seizures per day, depending on the number of hours of video monitoring or visual observation (Arida et al., 1999; Hoexter et al., 2005; Leite and Cavalheiro, 1995; Priel et al., 1996). Recent studies have, however, shown that without the use of continuous video-EEG monitoring the number of seizures can be underestimated, and also the determination of seizure duration is unreliable. Reliable analysis of these parameters is critical when performing studies investigating the phase of epileptogenesis or assessing the antiepileptogenic or antiepileptic effects of novel compounds.

In this study, we focused on the early phase of the epileptogenic process to address the following two questions. Firstly, what is the duration of latency period in pilocarpineinduced model of epilepsy? Secondly, what are the seizure characteristics at the early phase of newly diagnosed epilepsy in 
this model? To accomplish these tasks, we induced epileptogenesis with pilocarpine in rats and continuously video-EEG monitored them for up to 23 days.

\section{Materials and methods}

Twenty-nine adult male Wistar rats weighing 285-350 g were housed in a controlled environment (7 a.m./7 p.m. light/ dark cycle; $22 \pm 1{ }^{\circ} \mathrm{C}$ ) with free access to food and water. For EEG recordings, screw electrodes (Plastics One Inc.) were inserted into the skull bilaterally over the frontal cortex under sodium pentobarbital $(60 \mathrm{mg} / \mathrm{kg})-$ chloral hydrate $(100 \mathrm{mg} / \mathrm{kg})$ anesthesia (Nissinen et al., 2000). One week postoperatively, rats were subjected to SE induced by pilocarpine $(360 \mathrm{mg} / \mathrm{kg}$ intraperitoneally, i.p.; P 6503, Sigma). Methyl-scopolamine (1 $\mathrm{mg} / \mathrm{kg}$ subcutaneously; Sigma) was administered $30 \mathrm{~min}$ prior to pilocarpine to reduce its peripheral effects. If the rat did not develop SE within $45 \mathrm{~min}$, it received additional doses of pilocarpine until SE started $(110 \mathrm{mg} / \mathrm{kg}$ for first dose, $60 \mathrm{mg} / \mathrm{kg}$ for further doses). Eighteen rats needed no further injections. Four rats needed 1 additional injection of pilocarpine, 2 rats 2, 2 rats 3, 2 rats 4 , and 1 rat 9 additional injections of pilocarpine in order to develop SE. All animals received a single dose of diazepam (20 mg/kg, i.p.; Stesolid Novum, Dumex-Alpharma) 120 min after SE onset.

For continuous recording of EEG activity and for detection of spontaneous seizures, a video-supported EEG monitoring system was used [Nervus EEG recording system with Nervus Magnus (-32/8) Amplifier (Taugagreining), Time Lapse VCR and Panasonic Video Camera; for details, see Nissinen et al., 2000]. To assess the severity and duration of SE, spike analysis was done from a digitized EEG of the first $24 \mathrm{~h}$ after SE onset (spike duration $<70 \mathrm{~ms}$; Clampfit 9.0). For the detection of spontaneous seizures, EEG was screened visually on the computer screen. Electrographic seizure was defined as a discharge with frequency $>5 \mathrm{~Hz}$, amplitude $>2 \times$ baseline, and duration $>10 \mathrm{~s}$. If an electrographic seizure was detected, the behavioral severity was determined from the video recordings and classified according to the scoring system for focal seizures with secondary generalization for pilocarpine-induced seizures as defined by Veliskova (2006): score 1: staring with mouth clonus; score 2: automatisms; score 3: unilateral forelimb clonus; score 4: bilateral forelimb clonus; score 5: bilateral forelimb clonus with rearing and falling; score 6: tonic-clonic seizure. Seizures were further classified into 2 categories: (1) partial seizures (scores 1-3) or (2) secondarily generalized seizures (scores 4-6).

\section{Results}

Sixteen of 29 rats died in the course of pilocarpine-induced SE (average dose $443 \mathrm{mg} / \mathrm{kg}$ (360-919 $\mathrm{mg} / \mathrm{kg})$ ). In the present study all rats had generalized SE. Thirteen survivors were continuously monitored for 15 days $(n=5)$ or 23 days $(n=8)$.

To assess the severity and duration of SE, we counted the number of spikes during the first $24 \mathrm{~h}$ after the beginning of SE
(Fig. 1A). The number of spikes spontaneously decreased in both groups, with a trend towards faster reduction in the group of animals that did not develop recurrent spontaneous seizures (i.e., epilepsy) during the follow-up ( $p=0.07$ at $3 \mathrm{~h}$-time point, Student's $t$-test). Administration of diazepam at $2 \mathrm{~h}$ after SE resulted in the disappearance of spiking within 3-4 h. Spiking activity resumed slightly in both groups within the next $6-7 \mathrm{~h}$.

Spontaneous seizures occurred in 10 of 13 animals (77\%) (Figs. 1B and C). In the rat group with a single dose of pilocarpine $83 \%$ developed epilepsy, and in the rat group with multiple doses of pilocarpine $71 \%$ (no difference, $\chi^{2}$-test). The average seizure-free period lasted for $7.2 \pm 3.6$ days (mean $\pm \mathrm{SD}$, range 5.2-17.2, median 6.1, $n=10$ ) (Table 1). Cumulative analysis of seizures over time showed an average frequency of $2.6 \pm 1.9$ seizures per day. $67 \pm 21 \%$ of the seizures occurred
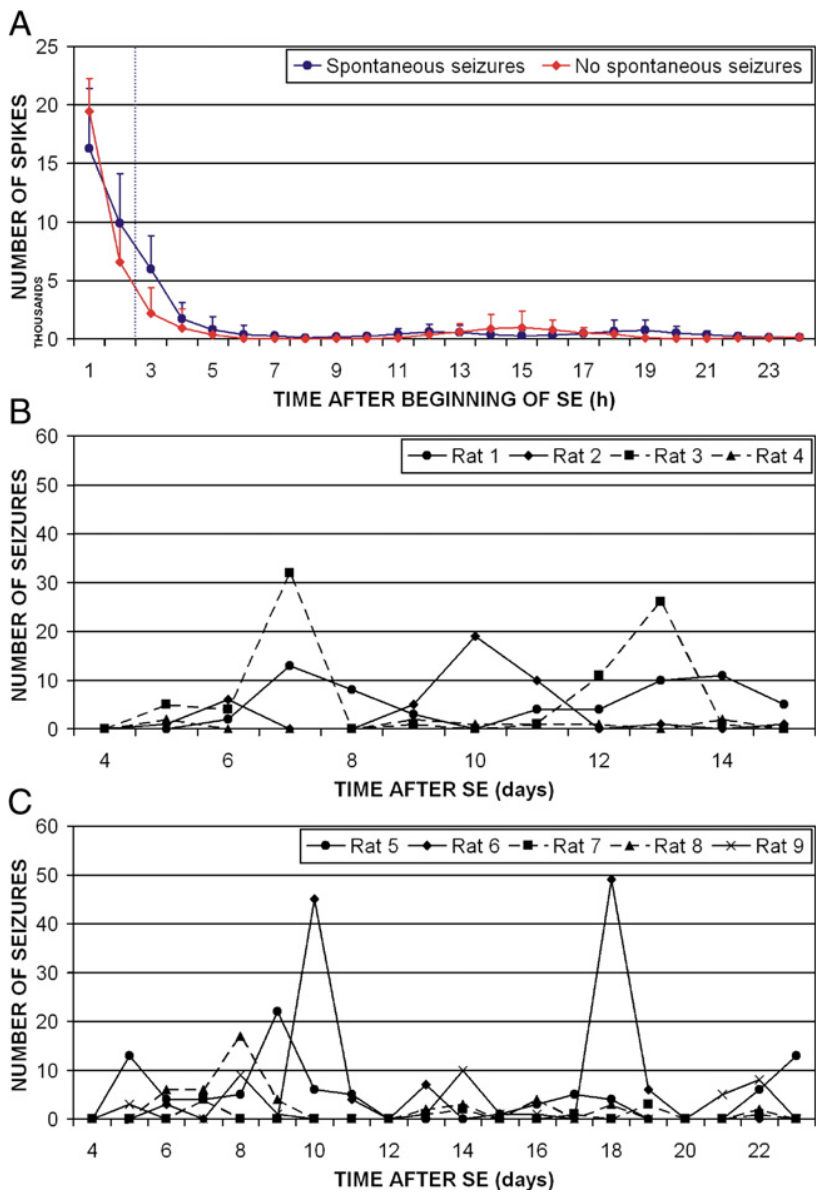

Fig. 1. (A) Number of epileptiform spikes ( $y$-axis, mean + standard deviation) at different time points after induction of status epilepticus (SE) ( $x$-axis, blue dashed line shows the administration of diazepam). Blue line indicates the data collected from the group of animals that developed spontaneous seizure $(n=10)$ and the red line from the group that did not $(n=3)$. Note that the number of spikes decreased in both groups within 1-2 $\mathrm{h}$ after administration of diazepam but the decrease tended to be more rapid in rats that did not develop epilepsy. (B, C) Number of spontaneous seizures per day ( $y$-axis) at different time points after SE ( $x$-axis). One animal only had a single seizure (17 days after SE) and is not included in the figure. Note that the first spontaneous seizures typically appeared at 5-7 days after SE in all 9 remaining animals. Furthermore, seizures occurred in cyclic pattern in all animals (peak of seizure frequency every 5-8 days). 
Table 1

Characteristics of spontaneous seizures in epileptic animals in pilocarpine mode

\begin{tabular}{lcccc}
\hline & Average & Median & SD & Range \\
\hline Duration of epileptogenesis (days) & 7.2 & 6.1 & 3.6 & $5.2-17.2$ \\
Number of seizures per day & 2.6 & 2.5 & 1.9 & $0.04-5.4$ \\
Seizure duration (seconds) & 47.0 & 47.3 & 7.0 & $35.2-51.2$ \\
Behavioral score & 3.2 & 3.2 & 0.9 & $1.3-5.0$ \\
\% of seizures with lights on & 66.9 & 64.7 & 20.7 & $42.6-100.0$ \\
\% of secondarily generalized seizures & 55.8 & 59.1 & 27.4 & $0.0-100.0$
\end{tabular}

between 7 a.m. and 7 p.m., when lights were on. The mean seizure duration was $47.0 \pm 7.0 \mathrm{~s}($ mean $\pm \mathrm{SD}$, range $35.2-51.2$, $n=10$ ) (Table 1). In all rats, seizures appeared in clusters (i.e., $>3$ seizures per day) (Arida et al., 1999), which were followed by a 'seizure-free' period. Furthermore, spontaneous seizures occurred in a cycle with a peak of seizure activity every 58 days (Figs. 1B and C). Behaviorally, spontaneous seizures were characterized by head nodding, forelimb clonus, rearing, and falling. In 8 of 10 animals, the first spontaneous seizure was partial, corresponding to stage 1 or 2 (Veliskova, 2006). In the remaining 2 animals, the first detected seizure was secondary generalized, corresponding to stage 4 or 5 (Veliskova, 2006). The average behavioral score of all seizures was $3.2 \pm 0.9$. When the animals were compared as a group, the behavioral score was significantly lower during the first 5 days of the chronic epileptic phase compared to the rest of the monitoring period ( $p=0.03$ as determined by one-way ANOVA with Bonferroni correction), indicating an increase in seizure severity as the epilepsy continued. Of all seizures, $56 \pm 27 \%$ were secondary generalized. The frequency and duration of seizures did not change significantly over time.

\section{Discussion}

As the present and previous studies show, one drawback of pilocarpine model of temporal lobe epilepsy is that a single high dose of pilocarpine does not always induce SE. Furthermore, a single high dose administration of pilocarpine is associated with a high mortality rate (Glien et al., 2001). In the present study, even though SE was interrupted with diazepam after $120 \mathrm{~min}$, the mortality rate was still $55 \%$. Interestingly, we did not observe a correlation between the dose of pilocarpine and the mortality. On the contrary, the average pilocarpine dose in survivors tended to be higher than that administered to rats that died $(p=0.056)$. This points to a high variability in the individual sensitivity to the convulsant action of pilocarpine. Whether this relates to a genetic variation within the Wistar rat strain remains to be studied (Glien et al., 2001).

We observed spontaneous seizures in $77 \%$ of the surviving rats which is lower than in most of the previous studies, where mostly all animals developed spontaneous seizures (Cavalheiro et al., 1991; Mello et al., 1993; Priel et al., 1996). On the contrary, dos Santos et al. only reported $61 \%$ of animals to develop spontaneous seizures (dos Santos et al., 2005). It is possible that more animals would have become epileptic if we had monitored them for a longer period of time. Interestingly, there was no difference in the dose of pilocarpine given to animals that did and did not develop epilepsy. The number of spikes counted during SE, however, tended to decrease more rapidly in the group of animals that did not develop epilepsy as compared to those who did, which is in line with previous studies in the perforant pathway model (Gorter et al., 2003; Pitkänen et al., 2005). Thus, it appears that independent of the SE model, the risk of epileptogenesis is associated with the duration and severity of SE in adult rats.

Previous analyses based on video or visual observation of animals suggest that the mean latency from SE to the appearance of spontaneous seizures varies from 10 to 18 days (Arida et al., 1999; Hoexter et al., 2005; Leite and Cavalheiro, 1995; Priel et al., 1996). In the present video-EEG study, the mean latency was only 7 days with substantial variability, which emphasizes the use of continuous video-EEG monitoring when there is a need of definition of the duration of latency period. The importance of continuous video-EEG monitoring was recently also emphasized by Williams et al., using radiotelemetry to investigate pharmacotherapy in epilepsy and epileptogenesis (Williams et al., 2006).

With respect to the phenotypical characteristics of the seizures, we found a similar seizure frequency, seizure duration and diurnal variation of seizures as described by Cavalheiro et al. (1991) and Arida et al. (1999), with frequencies of 1.9 and 1.4 seizures per day, respectively and seizure duration lower than $50-60 \mathrm{~s}$. It is noteworthy that there was a large variability between animals concerning the absolute number of seizures per day. For example, one animal only had one seizure during the entire monitoring period, while another animal had 45 seizures over a 24-h period. There was no relation between the severity of SE (number of spikes during the first $24 \mathrm{~h}$ ) and the subsequent seizure frequency. As described earlier, seizures appeared in clusters followed by a 'seizure-free' period (Arida et al., 1999; Cavalheiro et al., 1991, 2006; Mello et al., 1993). Interestingly, also in humans with temporal lobe epilepsy seizures can appear in clusters in a subpopulation of patients (Balish et al., 1991; Haut et al., 2002; Haut, 2006). Furthermore, we found that in the pilocarpine model, seizure clusters occur in a cyclic pattern of 5-8 days. Again, similar patterns have been described in humans with partial and secondarily generalized seizures in up to $50 \%$ of patients (Balish et al., 1991; Bauer and Burr, 2001). In humans, the cyclicity can obey a circadian (Bowman et al., 1984), circaseptin (6-8 days), or quasi-monthly pattern (Bauer and Burr, 2001). There is no general explanation for the phenomenon of seizure clustering or periodic patterns of seizure occurrence. Our study shows that studies using pilocarpine model could provide insights into both specific mechanisms of seizure clustering and cyclicity.

Similar to Cavalheiro et al. (1991), we found a progression in the severity of spontaneous seizures with mainly partial seizures during the first days after the development of spontaneous seizures and a significant increase in the average behavioral score in further monitoring episodes. Also after the first secondarily generalized seizure had occurred, rats remained 
Table 2

Comparison of seizure characteristics in different SE models of epilepsy in rat

\begin{tabular}{|c|c|c|c|c|}
\hline & Nissinen et al., 2000 & Mazarati et al., 2002 & Gorter et al., 2001 & Dudek et al., 2006 \\
\hline Method & $\begin{array}{l}\text { Electrical stimulation } \\
\text { of amygdala }\end{array}$ & $\begin{array}{l}\text { Electrical stimulation } \\
\text { of angular bundle }\end{array}$ & $\begin{array}{l}\text { Electrical tetanic stimulation } \\
\text { of hippocampus }\end{array}$ & $\begin{array}{l}\text { Systemic administration } \\
\text { of kainic acid }\end{array}$ \\
\hline Latency & 33 (6-85) days & $28(20-32)$ days & 7-9 days & $1-2$ weeks, may be longer \\
\hline $\begin{array}{l}\text { Evolution of } \\
\text { seizure } \\
\text { frequency }\end{array}$ & $\begin{array}{l}\text { Increase during the first } \\
3 \text { months - stable } \\
\text { during the next } 3 \text { months }\end{array}$ & $\begin{array}{l}\text { Initial increase reaching } \\
\text { a stable plateau }\end{array}$ & $\begin{array}{l}\text { Increase in } 67 \% \text { of animals } \\
\text { during the first } 2 \text { months }\end{array}$ & Increase over time after $\mathrm{SE}$ \\
\hline $\begin{array}{l}\text { Behavioral } \\
\text { appearance of } \\
\text { spontaneous } \\
\text { seizures }\end{array}$ & $\begin{array}{l}\text { During the first } 10 \text { weeks } \\
79 \% \text { of seizures are } \\
\text { secondary generalized. } \\
\text { Thereafter, } 77 \% \text { of } \\
\text { seizures are partial. }\end{array}$ & $\begin{array}{l}\text { In } 30 \% \text { of rats the first } \\
\text { seizure is partial with } \\
\text { evolution to secondarily } \\
\text { generalized seizure after } \\
14 \text { seizures. } \\
\text { In } 70 \% \text { of rats the first } \\
\text { seizure is secondary generalized, } \\
\text { no evolution. }\end{array}$ & $\begin{array}{l}\text { For the first } 2 \text { months } \\
\text { seizures are secondary } \\
\text { generalized (Racine class IV-V), } \\
\text { thereafter class I-III }\end{array}$ & $\begin{array}{l}\text { Motor seizures, Racine } \\
\text { class III-V }\end{array}$ \\
\hline
\end{tabular}

having a mixture of partial and secondarily generalized seizures. We did not find a significant change in the seizure frequency and duration over time.

An overview of the main phenotypical characteristics of other models of spontaneous seizures is given in Table 2. It is noteworthy that there is a wide spread in the mean latency period going from 1 week to 1 month and in the seizure frequency with higher values in the kainate model. All models show an increase in seizure frequency during the first weeks of monitoring until a plateau has been reached. Thereafter, the seizure frequency stays more or less stable. The seizure duration is similar throughout the different models. In models using electrical stimulation, seizures are mainly secondary generalized during the first months, but decrease in severity as the epilepsy continues. Interestingly, if the first seizures after $\mathrm{SE}$ are partial, there is an increase in seizure severity over the next seizures until secondarily generalized seizures appear. Most animals, however, remain having a combination of partial and secondarily generalized seizures. This behavioral evolution is similar to the one described in the pilocarpine model.

The present study shows that the latency period is short in pilocarpine model of temporal lobe epilepsy. Continuous long-term video-EEG monitoring is of great help to reliably define the interindividual variability in seizure frequency, seizure type, and occurrence of cyclicity. Our data also suggest that the pilocarpine model can offer a useful tool for studies aiming at understanding the mechanisms of seizure clustering.

\section{Acknowledgments}

We thank Mr. Jarmo Hartikainen for his invaluable assistance in the animal preparation. This work was financially supported by the Flemish Fund for Scientific Research (G.0227.05) to KG and The Academy of Finland and The Juselius Foundation to AP. KG is Research Assistant and KVL is Senior Clinical Investigator of the Flemish Fund of Scientific Research.

\section{References}

Arida, R.M., Scorza, F.A., Peres, C.A., Cavalheiro, E.A., 1999. The course of untreated seizures in the pilocarpine model of epilepsy. Epilepsy Res. 34, 99-107.

Balish, M., Albert, P.S., Theodore, W.H., 1991. Seizure frequency in intractable partial epilepsy: a statistical analysis. Epilepsia 32, 642-649.

Bauer, J., Burr, W., 2001. Course of chronic focal epilepsy resistant to anticonvulsant treatment. Seizure 10, 239-246.

Bowman, T., Leppik, I., Haus, E., 1984. Periodicity of seizure activity in persons with complex partial seizures. Epilepsia 25, 658.

Cavalheiro, E.A., Leite, J.P., Bortolotto, Z.A., Turski, W.A., Ikonomidou, C., Turski, L., 1991. Long-term effects of pilocarpine in rats: structural damage of the brain triggers kindling and spontaneous recurrent seizures. Epilepsia 32, 778-782.

Cavalheiro, E.A., Naffah-Mazzacoratti, M.G., Mello, L.E., Leite, J.P., 2006. The pilocarpine model of seizures. In: Pitkänen, A., Schwartskroin, P.A., Solomon, L.M. (Eds.), Models of Seizures and Epilepsy. Elsevier Academic Press, Burlington, pp. 433-448.

dos Santos Jr., J.G., Longo, B.M., Blanco, M.M., Menezes de Oliveira, M.G., Mello, L.E., 2005. Behavioral changes resulting from the administration of cycloheximide in the pilocarpine model of epilepsy. Brain Res. 1066, 37-48.

Dudek, F.E., Clark, S., Williams, P.A., Grabenstatter, H.L., 2006. Kainateinduced status epilepticus: a chronic model of acquired epilepsy. In: Pitkänen, A., Schwartskroin, P.A., Solomon, L.M. (Eds.), Models of Seizures and Epilepsy. Elsevier Academic Press, Burlington, pp. 415-432.

Glien, M., Brandt, C., Potschka, H., Voigt, H., Ebert, U., Loscher, W., 2001. Repeated low-dose treatment of rats with pilocarpine: low mortality but high proportion of rats developing epilepsy. Epilepsy Res. 46, 111-119.

Gorter, J.A., van Vliet, E.A., Aronica, E., Lopes da Silva, F.H., 2001 Progression of spontaneous seizures after status epilepticus is associated with mossy fiber sprouting and extensive bilateral loss of hilar parvalbumin and somatostatin-immunoreactive neurons. Eur. J. Neurosci. 13, 657-669.

Gorter, J.A., Goncalves Pereira, P.M., van Vliet, E.A., Aronica, E., Lopes da Silva, F.H., Lucassen, P.J., 2003. Neuronal cell death in a rat model of mesial temporal lobe epilepsy is induced by the initial status epilepticus and not by later repeated spontaneous seizures. Epilepsia 44, 647-658.

Haut, S.R., 2006. Seizure clustering. Epilepsy Behav. 8, 50-55. 
Haut, S.R., Swick, C., Freeman, K., Spencer, S., 2002. Seizure clustering during epilepsy monitoring. Epilepsia 43, 711-715.

Hoexter, M.Q., Rosa, P.S., Tufik, S., Mello, L.E., 2005. Consequences of prolonged caffeine administration and its withdrawal on pilocarpine- and kainite-induced seizures in rats. Epilepsia 46, 1401-1406.

Leite, J.P., Cavalheiro, E.A., 1995. Effects of conventional antiepileptic drugs in a model of spontaneous recurrent seizures in rats. Epilepsy Res. 20, 93-104.

Mazarati, A., Bragin, A., Baldwin, R., Shin, D., Wilson, C., Sankar, R., Naylor, D., Engel, J., Wasterlain, C.G., 2002. Epileptogenesis after self-sustaining status epilepticus. Epilepsia 43, 74-80.

Mello, L.E., Cavalheiro, E.A., Tan, A.M., Kupfer, W.R., Pretorius, J.K., Babb, T.L., Finch, D.M., 1993. Circuit mechanisms of seizures in the pilocarpine model of chronic epilepsy: cell loss and mossy fiber sprouting. Epilepsia 34, 985-995.

Nissinen, J., Halonen, T., Koivisto, E., Pitkänen, A., 2000. A new model of chronic temporal lobe epilepsy induced by electrical stimulation of the amygdala in rat. Epilepsy Res. 38, 177-205.

Pitkänen, A., Kharatishvili, I., Narkilahti, S., Lukasiuk, K., Nissinen, J., 2005. Administration of diazepam during status epilepticus reduces development and severity of epilepsy in rat. Epilepsy Res. 63, 27-42.
Priel, M.R., dos Santos, N.F., Cavalheiro, E.A., 1996. Developmental aspects of the pilocarpine model of epilepsy. Epilepsy Res. 26, 115-121.

Turski, W.A., Cavalheiro, E.A., Schwarz, M., Czuczwar, S.J., Kleinrok, Z., Turski, L., 1983. Limbic seizures produced by pilocarpine in rats: a behavioural, electroencephalographic and neuropathologic study. Behav. Brain Res. 9, 315-335.

Turski, W.A., Cavalheiro, E.A., Bortolotto, Z.A., Mello, L.M., Schwarz, M., Turski, L., 1984. Seizures produced by pilocarpine in mice: a behavioral, electroencephalographic and morphological analysis. Brain Res. 321, 237-253.

Turski, L., Ikonomidou, C., Turski, W.A., Bortolotto, Z.A., Cavalheiro, E.A., 1989. Review: cholinergic mechanisms and epileptogenesis. The seizures induced by pilocarpine: a novel experimental model of intractable epilepsy. Synapse 3, 154-171.

Veliskova, J., 2006. Behavioral characterization of seizures in rats. In: Pitkänen, A., Schwartskroin, P.A., Solomon, L.M. (Eds.), Models of Seizures and Epilepsy. Elsevier Academic Press, Burlington, pp. 601-611.

Williams, P., White, A., Ferraro, D., Clark, S., Staley, K., Dudek, F.E., 2006. The use of radiotelemetry to evaluate electrographic seizures in rats with kainateinduced epilepsy. J. Neurosci. Methods 15, 39-48. 